\title{
Diet quality, physical activity, body weight and health-related quality of life among grade 5 students in Canada
}

\author{
Xiu Yun Wu, Arto Ohinmaa* and Paul J Veugelers \\ Department of Public Health Sciences, School of Public Health, University of Alberta, 3-50 M University Terrace, \\ 8303 - 112 Street, Edmonton, Alberta, Canada T6G 2T4
}

Submitted 7 April 2011: Accepted 1 September 2011: First published online 4 October 2011

\begin{abstract}
Objective: To assess how diet quality, physical activity and body weight are related to health-related quality of life (HRQOL) among children in the Canadian province of Alberta.

Design: In 2008, we surveyed 3421 grade 5 students and their parents from 148 randomly selected schools. Students completed the Harvard Food Frequency Questionnaire, questions on physical activities, and had their height and weight measured. The HRQOL of the students was assessed using the EQ-5D-Y. Parents completed questions on socio-economic background and children's lifestyle. We applied multilevel regression methods to examine the importance of children's diet quality, physical activity and weight status for the EQ-5D-Y Visual Analogue Scale and for the EQ-5D-Y dimensions.

Setting: The province of Alberta, Canada.

Subjects: Grade 5 students.

Results: Students with better diet quality, higher physical activity levels and normal body weights were statistically significantly more likely to report better HRQOL than students who ate less healthily, were less active or were overweight or obese.

Conclusions: The importance of diet quality, physical activity and body weight status for HRQOL may help justify broader implementation of school health programmes that promote healthy eating and active living, as these programmes will help reduce the burden of childhood obesity and improve quality of life.
\end{abstract}

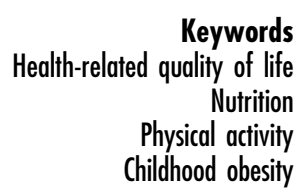

Excess body weight has become a public health burden in both developing and developed countries ${ }^{(1)}$. In Canada, $25.7 \%$ of children and adolescents are overweight or obese, and $8.6 \%$ obese $^{(2)}$. Excess body weight has been widely acknowledged to contribute to various chronic diseases, resulting in diminished life expectancy ${ }^{(3-5)}$. Overweight or obesity in children and adolescents has also negative consequences for self-esteem, psychosocial health and cognitive development ${ }^{(6-8)}$.

Unhealthy diet, characterized by increased intakes of fat and sugar and inadequate intakes of fruits, vegetables and whole grains ${ }^{(9)}$, as well as insufficient physical activity (PA) have been identified as two fundamental factors leading to overweight and obesity ${ }^{(10,11)}$. Most childhood obesity strategies therefore include the combination of promotion of healthy eating and active living ${ }^{(12,13)}$. Such approaches have also been shown to benefit self-esteem and academic performance ${ }^{(6,9,13,14)}$.

The importance of excess body weight for impaired health-related quality of life (HRQOL) in children and adolescents has been documented in both clinical and population-based studies ${ }^{(15-22)}$. However, only a few studies have looked at the importance of the factors underlying excess body weight - being diet quality and PA - for HRQOL. Moreover, the few that have were conducted were mostly among children and adolescents with chronic diseases or specific health conditions ${ }^{(19,23,24)}$. Very few studies on diet quality, PA and weight status in relation to HRQOL in children used representative population-based samples ${ }^{(25-26)}$. Although such studies are important in identifying the undesired dietary and activity patterns and in designing effective intervention strategies, no such studies have been conducted in Canada. The purpose of the present study was therefore to establish the associations of diet quality, PA and weight status with HRQOL among children in Canada.

\section{Methods}

\section{The survey}

The Raising Healthy Eating and Active Living Kids in Alberta (REAL Kids Alberta) survey was developed to evaluate Alberta Health and Wellness initiatives that promote healthy body weights among children and adolescents. The survey was conducted in 2008 among grade 5 students 
who are primarily 10 to 11 years old. The survey employed a one-stage stratified random sampling design. The sampling frame includes all elementary schools in the province with the exception of private schools $(4 \cdot 7 \%$ of all Alberta children), francophone schools ( $0.6 \%)$, on-reserve federal schools $(2 \cdot 0 \%)$, charter schools $(1 \cdot 7 \%)$ and colony schools $(0.8 \%)^{(27)}$, leaving primarily public and Catholic schools in the sampling frame. Schools were stratified into three geographies: (i) urban, i.e. Calgary and Edmonton; (ii) cities, i.e. other municipalities with more than 40000 residents; and (iii) rural, i.e. municipalities with fewer than 40000 residents. Schools were randomly selected within each of these three strata to achieve a balanced number of schools and students in each stratum.

Of the 184 invited schools, $148(80 \cdot 4 \%)$ participated in the study. All grade 5 students ( $n$ 5594) attending these schools received an envelope with a consent form and a survey to take home for their parent/guardian(s) to complete. A total of 3645 students returned the forms and had received parental consent to participate in the study. In total, 3421 students (61.2\% of all students) completed the survey when trained assistants visited their schools to administer the surveys and to measure heights and weights. The surveys included questions on nutrition, PA and HRQOL measured by the youth version of the EQ-5D $(E Q-5 D-Y)^{(28)}$. The questionnaires, both for students and parents, are posted online (www.REALKidsAlberta.ca).

\section{Assessments}

\section{Diet quality assessment}

The Harvard Food Frequency Questionnaire for Youth and Adolescents (YAQ) is a validated food frequency instrument that is suitable for grade 5 students $^{(29,30)}$. The YAQ provides detailed information on the frequency and kinds of foods that children and adolescents consume ${ }^{(29)}$. On the basis of students' responses to the YAQ and Canadian Nutrient Files $^{(31)}$, we calculated intakes of nutrients and energy for each participant. On the basis of these intakes we determined the diet quality using the Diet Quality IndexInternational (DQI-I) composite measure. The DQI-I encompasses variety, adequacy, moderation and overall balance of the diet ${ }^{(32)}$. We divided the DQI-I scores into tertiles for the purpose of our analysis.

\section{Physical activity assessment}

Students and their parent/guardian(s) responded to questions on: (i) travel to and from school; (ii) time spent to get to and from school; (iii) frequency of child's activities outside school hours; (iv) activities at morning and lunch recess in the past $7 \mathrm{~d}$; and (v) frequency of involvement in sports and physical activities in the past $7 \mathrm{~d}$. These questions, containing twenty-nine items, were largely adopted from the Physical Activity Questionnaire for Children (PAQ-C) which has been demonstrated to be valid and have high reliability ${ }^{(33,34)}$. We derived a composite score ranging from 0 to 5 based on the score given to the twenty-nine items.

\section{Overweight and obesity assessment}

Standing height was measured to the nearest $0.1 \mathrm{~cm}$ without shoes and body weight to the nearest $0 \cdot 1 \mathrm{~kg}$ on calibrated digital scales. BMI was calculated by dividing weight (in kilograms) by the square of height (in metres). Body weight was categorized as normal weight, overweight and obese using the BMI cut-off points for children and adolescents by the International Obesity Taskforce ${ }^{(35)}$. These cut-offs are based on adult definitions of overweight $\left(25 \mathrm{~kg} / \mathrm{m}^{2}\right.$ or more) and obesity $\left(30 \mathrm{~kg} / \mathrm{m}^{2}\right.$ or more), adjusted to specific age and gender groups for children.

\section{Outcome measures}

HRQOL was assessed by the EQ-5D-Y (youth) where the language of the EQ-5D instrument for adults is modified so that children can better understand it. The HRQOL instrument consists of a five-dimensional descriptive system asking whether children have (i) no problems, (ii) some problems or (iii) a lot of problems with: (i) walking; (ii) looking after myself; (iii) doing usual activities; (iv) having pain or discomfort; and (v) feeling worried, sad or unhappy, respectively ${ }^{(28)}$. The instrument also includes a Visual Analogue Scale (VAS) which is anchored at 100 (best imaginable health) and 0 (worst imaginable health) to capture self-rated values of health status in children. The EQ-5D-Y has been validated for several languages and countries ${ }^{(36)}$. The main advantages of the instrument are that it is short and simple, can be completed within 10 min by children, and can be used to estimate a single index score to be analysed subsequently in economic evaluation studies ${ }^{(28)}$.

\section{Analytical methods}

We applied the $\chi^{2}$ test to examine differences in the prevalence of reported health problems for each of the five EQ-5D-Y dimensions by the observed predictors. As very few students reported 'a lot of problems', we combined this with 'some problems' to create a dichotomous outcome (no problems $v$. with any problems). We described generic HRQOL by different groups of diet quality, PA and weight status as measured by the EQ-5D-Y VAS score. We applied multilevel multivariable linear regression to assess the association of diet quality, PA and body weight with the generic HRQOL. We applied multilevel multivariable logistic regression to examine the effect of diet quality, PA and body weight for the EQ-5D-Y dimensions. These regression models accommodated the hierarchical data structure in that student observations are nested within their schools. The regression analyses were adjusted for the confounding influence of gender, place of residence, household income and parental education.

The EQ-5D-Y descriptive system was fully completed by 3406 students $(99 \cdot 6 \%)$ and 3379 students (98.8\%) 
answered the VAS. These missing outcomes were not considered in the analyses. Of all participating students, 3340 parents completed a survey on educational attainment, household income, place of residency (urban, town, rural) and their child's PA. Missing values for education and income were considered as separate categories in the analysis but the estimates are not presented. All analyses were weighted to accommodate the design effect such that all estimates pertain to the population of grade 5 students in Alberta. Data were analysed using the STATA statistical software package version 11.0 (StataCorp, College Station, TX, USA). The study programme was approved by Health Research Ethics Board of the University of Alberta.

\section{Results}

Students who were physically inactive reported significantly more HRQOL problems relative to their peers who were physically active on four of the five dimensions: 'looking after myself', 'doing usual activities', 'having pain or discomfort', and 'feeling worried, sad or unhappy'. Compared with the normal weight group, obese students had significantly more HRQOL problems on the 'looking after myself' and 'feeling worried, sad or unhappy' dimensions. Furthermore, across diet quality tertiles, statistically significant differences were reported with respect to 'having pain or discomfort' (Table 1). Mean HRQOL score for students in the highest tertile of diet quality, with physically active lifestyle and with healthy weight was $82 \cdot 2,84 \cdot 2$ and $81 \cdot 5$, respectively (Table 1 ).

Table 2 shows multivariate-adjusted associations of HRQOL with diet quality, PA and body weight status. The VAS value was statistically significantly higher for students who were physically active, normal weight and in the highest DQI-I tertile relative to students who were not physically active, overweight or obese and in the lowest DQI-I tertile.

Table 3 presents the adjusted odds ratio of reporting problems on the EQ-5D-Y dimensions. Diet quality, body weight status and PA significantly affected one, two and four of the five dimensions, respectively, after accounting for the effect of sociodemographic variables. The results are very similar to the unadjusted results in Table 1.

\section{Discussion}

The present study reveals that diet quality, PA and body weight are associated with HRQOL in grade 5 students. These associations were independent of gender and sociodemographic factors. The study further reveals an association of diet quality with the VAS score whereby children with better diet quality reported better HRQOL. Students who were physically inactive, overweight or obese had reportedly a lower HRQOL.

The relationship between PA and HRQOL has been well described in adults relative to younger populations. An association of higher HRQOL scores with higher PA levels has been consistently documented in healthy adults $^{(37)}$. Our observations that physically active children have significantly higher HRQOL scores than those in the inactive group support the previous findings in both adult $^{(37)}$ and the few child and adolescent studies ${ }^{(25,26,38,39)}$. A systematic review of HRQOL among children and adolescents reported that excess body weight had a moderate to strong negative influence on HRQOL, whereas the role of psychosocial, emotional and school functioning on HRQOL had been inconsistent ${ }^{(40)}$. Our observation in a large population-based sample of grade 5 students confirms this relationship of excess body weight with lower quality of life. We also showed that children from parents who received

Table 1 Prevalence of problems in the EQ-5D-Y dimensions and mean VAS score by diet quality, physical activity and weight status: grade 5 students aged $10-11$ years ( $n$ 3421), Alberta, Canada, 2008

\begin{tabular}{|c|c|c|c|c|c|c|c|c|}
\hline \multirow[b]{2}{*}{ Variable } & \multirow[b]{2}{*}{$\begin{array}{l}\text { Percentage } \\
(n 3421)\end{array}$} & \multicolumn{5}{|c|}{ Percentage of students reporting having problems with: } & \multicolumn{2}{|c|}{ VAS score* } \\
\hline & & Walking & $\begin{array}{l}\text { Looking after } \\
\text { myself }\end{array}$ & $\begin{array}{l}\text { Doing usual } \\
\text { activities }\end{array}$ & $\begin{array}{l}\text { Having pain or } \\
\text { discomfort }\end{array}$ & $\begin{array}{l}\text { Feeling worried, } \\
\text { sad or unhappy }\end{array}$ & Mean & $95 \% \mathrm{Cl}$ \\
\hline $\begin{array}{l}\text { All grade } 5 \text { students } \\
\text { DQI-I }\end{array}$ & $100 \cdot 0$ & $\begin{aligned} & 8 \cdot 1 \\
P= & 0.894\end{aligned}$ & $\begin{aligned} & 6.5 \\
P= & 0.698\end{aligned}$ & $\begin{array}{c}11.9 \\
P=0.274\end{array}$ & $\begin{array}{c}46 \cdot 1 \\
P=0.049\end{array}$ & $\begin{array}{c}37 \cdot 7 \\
P=0.388\end{array}$ & $80 \cdot 4$ & $79 \cdot 8,81 \cdot 1$ \\
\hline Lowest tertile & - & 8.4 & $7 \cdot 0$ & $13 \cdot 1$ & $49 \cdot 2$ & $39 \cdot 4$ & $78 \cdot 5$ & $77 \cdot 4,79 \cdot 5$ \\
\hline Middle tertile & - & $8 \cdot 2$ & $6 \cdot 4$ & $11 \cdot 7$ & $43 \cdot 6$ & $36 \cdot 4$ & $80 \cdot 5$ & $79 \cdot 4,81 \cdot 6$ \\
\hline Highest tertile & - & $7 \cdot \overline{8}$ & $6 \cdot 0$ & $10 \cdot 8$ & $45 \cdot 6$ & $37 \cdot 3$ & $82 \cdot 2$ & $81 \cdot 1,83 \cdot 2$ \\
\hline Physical activity & & $P=0 \cdot 112$ & $P=0.005$ & $P<0.001$ & $P=0.003$ & $P<0.001$ & & \\
\hline Not active & 73.9 & 8.6 & $7 \cdot 3$ & $13 \cdot 4$ & $47 \cdot 7$ & $39 \cdot 9$ & $79 \cdot 1$ & $78 \cdot 3,79 \cdot 8$ \\
\hline Active & $26 \cdot 1$ & $6 \cdot 8$ & $4 \cdot 4$ & $7 \cdot 6$ & $41 \cdot 5$ & $31 \cdot 4$ & $84 \cdot 2$ & $83 \cdot 1,85 \cdot 2$ \\
\hline Weight category & & $P=0.146$ & $P=0.009$ & $P=0.170$ & $P=0.440$ & $P=0.035$ & & \\
\hline Obese & $7 \cdot 0$ & $10 \cdot 8$ & $11 \cdot 7$ & $15 \cdot 8$ & $49 \cdot 8$ & $46 \cdot 0$ & $75 \cdot 4$ & $73 \cdot 1,77 \cdot 8$ \\
\hline $\begin{array}{l}\text { Overweight } \\
\text { (excluding obese) }\end{array}$ & $21 \cdot 7$ & $9 \cdot 2$ & $6 \cdot 3$ & $12 \cdot 2$ & $47 \cdot 1$ & $38 \cdot 3$ & $78 \cdot 5$ & $77 \cdot 1,79 \cdot 9$ \\
\hline Normal weight & $71 \cdot 3$ & $7 \cdot 6$ & $6 \cdot 1$ & $11 \cdot 4$ & $45 \cdot 5$ & $36 \cdot 7$ & $81 \cdot 5$ & $80 \cdot 8,82 \cdot 2$ \\
\hline
\end{tabular}

VAS, Visual Analogue Scale; DQI-I, Diet Quality Index-International.

The $\chi^{2}$ test was used to obtain the $P$ values where weighted percentages of students with problems in different dimensions are presented.

*The EQ-5D-Y VAS score ranged from 0 to 100 , where 100 is best imaginable health. 
Table 2 Associations of diet quality, physical activity, body weight status and sociodemographic factors with VAS score*: grade 5 students aged $10-11$ years ( $n$ 3421), Alberta, Canada, 2008

\begin{tabular}{|c|c|c|c|}
\hline Variable & Regression coefficient & $95 \% \mathrm{Cl}$ & $P$ value \\
\hline Constant & $75 \cdot 97$ & $73 \cdot 43,78 \cdot 52$ & $<0.001$ \\
\hline \multicolumn{4}{|l|}{ DQI-I (reference: lowest tertile) } \\
\hline Middle tertile & $1 \cdot 47$ & $-0 \cdot 22,3 \cdot 15$ & 0.088 \\
\hline Highest tertile & $2 \cdot 76$ & $1 \cdot 26,4 \cdot 26$ & $<0.001$ \\
\hline \multicolumn{4}{|c|}{ Physical activity (reference: not active) } \\
\hline Active & $4 \cdot 49$ & $2 \cdot 98,6 \cdot 00$ & $<0.001$ \\
\hline \multicolumn{4}{|c|}{ Weight status (reference: normal weight) } \\
\hline Overweight (excluding obese) & $-2 \cdot 48$ & $-4 \cdot 00,-0.96$ & 0.001 \\
\hline Obese & $-5 \cdot 39$ & $-7 \cdot 64,-3 \cdot 13$ & $<0.001$ \\
\hline Gender (boys relative to girls) & 0.47 & $-0 \cdot 96,1 \cdot 90$ & 0.517 \\
\hline \multicolumn{4}{|l|}{ Residential area (reference: urban) } \\
\hline Town & $0 \cdot 22$ & $-1 \cdot 95,2 \cdot 40$ & $0 \cdot 840$ \\
\hline Rural & 1.45 & $-0 \cdot 28,3 \cdot 19$ & $0 \cdot 100$ \\
\hline \multicolumn{4}{|c|}{ Parents' education (reference: secondary or below) } \\
\hline Post-secondary or college & $1 \cdot 18$ & $-0 \cdot 41,2 \cdot 76$ & $0 \cdot 147$ \\
\hline University or above & $2 \cdot 42$ & $0 \cdot 76,4 \cdot 09$ & 0.004 \\
\hline \multicolumn{4}{|c|}{ Household income (reference: $\leq \$ C A N 50000$ ) } \\
\hline \$CAN $50001-75000$ & -0.84 & $-3 \cdot 45,1 \cdot 76$ & 0.524 \\
\hline \$CAN 75001-100000 & $0 \cdot 80$ & $-1 \cdot 33,2 \cdot 92$ & 0.462 \\
\hline$>\$ C A N 100000$ & $1 \cdot 41$ & $-0.46,3 \cdot 28$ & $0 \cdot 139$ \\
\hline
\end{tabular}

VAS, Visual Analogue Scale; DQI-I, Diet Quality Index-International.

The regression analysis was mutually adjusted for variables in the table. All estimates were weighted to represent population estimates.

${ }^{*}$ The EQ-5D-Y VAS score ranged from 0 to 100 , where 100 is best imaginable health.

less education had lower quality of life. Identifying determinants for different aspects of the HRQOL is essential to developing public health intervention strategies and targets. Our study revealed that PA has a significant impact on each of the five EQ-5D-Y dimensions except 'walking'. This is consistent with the few previous studies that have demonstrated that physically active children exhibit better physical and psychological quality of life ${ }^{(26)}$, better self-esteem ${ }^{(41)}$ and better psychosocial quality of life ${ }^{(19,41)}$. We observed that overweight and obese children were reportedly more worried, sad or unhappy, which seems consistent with HRQOL studies reporting that obesity is associated with impaired psychosocial functioning ${ }^{(17,18,21,22)}$, lower physical functioning ${ }^{(40)}$, lower emotional functioning ${ }^{(16,22)}$ and lower self-esteem $^{(17,22)}$.

Relative to studies in other countries using the EQ-5D-Y, children in Alberta reported a higher prevalence of health problems in the dimension of pain or discomfort (46.0\%). High percentage of any health problems in pain or discomfort ( $43.6 \%$ ) was also presented in a general population sample of adults in Alberta using the EQ-5D ${ }^{(42)}$. A possible explanation for this finding in our study may be that response to the EQ-5D-Y descriptive system could be culturally different across different countries or in geographic areas within a country. Further analysis using the EQ-5D-Y in other provinces in Canada and in other countries may help to ascertain the origin of this finding.

In addition, it is also important to examine the magnitude of the differences to estimate minimally important differences (MID) in HRQOL scores between comparison groups ${ }^{(43)}$. MID for the EQ-5D index and the EQ-5D VAS have been previously estimated for some disease conditions ${ }^{(44,45)}$. We have not identified any study demonstrating a MID value for the EQ-5D-Y VAS or index. Estimation of MID in HRQOL scores requires a variety of approaches, both distribution-based and anchor-based ${ }^{(46)}$, and a rigorous examination of various factors that may affect the degree of minimal differences ${ }^{(47)}$. Future research is warranted to investigate the magnitude and direction of differences/changes in HRQOL to establish MID cut-off points for the EQ-5D-Y for the general population of children and adolescents.

In the present study we did not estimate an index score for EQ-5D-Y as we were interested in quality of life that was measured and described by children themselves. Since no EQ-5D-Y tariff is available for use in younger populations, several previous studies in quality of life assessment in children and adolescents using the EQ-5D or EQ-5D-Y have reported on utility indices generated from the existing US or UK EQ-5D tariffs ${ }^{(48,49)}$. There is a debate about the applicability of the existing social tariffs for adults to children ${ }^{(36)}$. Current research interest in the field is to establish a child-specific value set for the EQ-5D-Y for use in population health research and economic evaluation studies ${ }^{(36)}$.

The present study is the first to reveal the associations of diet quality, PA and body weight with HRQOL among preteen children. Specifically, the study contributes to the evidence of positive associations between diet quality, PA and HRQOL in schoolchildren, independently of weight status and sociodemographic characteristics. These findings suggest that school-based programmes promoting healthy eating and active living may not only help to prevent children from becoming overweight, but may also benefit their HRQOL regardless of weight status. The differences in HRQOL outcomes by diet quality specifically 
Table 3 Odds ratio of reporting problems in the EQ-5D-Y dimensions by diet quality, physical activity, weight status and sociodemographic factors: grade 5 students aged $10-11$ years ( $n 3421$ ), Alberta, Canada, 2008

\begin{tabular}{|c|c|c|c|c|c|c|c|c|c|c|c|c|c|c|c|}
\hline \multirow{2}{*}{ Variable } & \multicolumn{3}{|c|}{ Walking } & \multicolumn{3}{|c|}{ Looking after myself } & \multicolumn{3}{|c|}{ Doing usual activities } & \multicolumn{3}{|c|}{ Having pain or discomfort } & \multicolumn{3}{|c|}{ Feeling worried, sad or unhappy } \\
\hline & OR & $95 \% \mathrm{Cl}$ & $P$ value & OR & $95 \% \mathrm{Cl}$ & $P$ value & OR & $95 \% \mathrm{Cl}$ & $P$ value & OR & $95 \% \mathrm{Cl}$ & $P$ value & OR & $95 \% \mathrm{Cl}$ & $P$ value \\
\hline \multicolumn{16}{|l|}{ DQI-I (reference: lowest tertile) } \\
\hline Middle tertile & 1.01 & $0 \cdot 70,1 \cdot 46$ & 0.941 & 0.94 & $0 \cdot 67,1 \cdot 31$ & $0 \cdot 710$ & 0.92 & $0 \cdot 70,1 \cdot 21$ & 0.538 & $0 \cdot 81$ & $0.68,0.98$ & 0.026 & $0 \cdot 88$ & $0.73,1.07$ & $0 \cdot 193$ \\
\hline Highest tertile & 0.98 & $0 \cdot 68,1 \cdot 41$ & $0 \cdot 918$ & 0.89 & $0.63,1.25$ & 0.495 & $0 \cdot 84$ & $0 \cdot 63,1 \cdot 12$ & 0.234 & $0 \cdot 90$ & $0.75,1.08$ & 0.254 & 0.92 & $0 \cdot 77,1 \cdot 11$ & 0.393 \\
\hline \multicolumn{16}{|c|}{ Physical activity (reference: active) } \\
\hline Not active & $1 \cdot 29$ & $0 \cdot 92,1 \cdot 81$ & $0 \cdot 140$ & $1 \cdot 71$ & $1 \cdot 21,2 \cdot 43$ & 0.002 & $1 \cdot 82$ & $1 \cdot 37,2 \cdot 42$ & $<0.001$ & $1 \cdot 29$ & $1 \cdot 06,1 \cdot 58$ & 0.012 & $1 \cdot 31$ & $1 \cdot 11,1 \cdot 54$ & 0.001 \\
\hline \multicolumn{16}{|l|}{$\begin{array}{l}\text { Weight category (reference: } \\
\text { normal weight) }\end{array}$} \\
\hline Overweight & $1 \cdot 20$ & $0.90,1.59$ & $0 \cdot 210$ & 1.04 & $0 \cdot 70,1 \cdot 53$ & 0.860 & 1.02 & $0 \cdot 79,1 \cdot 31$ & 0.901 & 1.04 & $0.84,1 \cdot 28$ & 0.735 & 1.04 & $0 \cdot 87,1 \cdot 26$ & 0.654 \\
\hline Obesity & $1 \cdot 38$ & $0.91,2 \cdot 07$ & $0 \cdot 128$ & 2.05 & $1 \cdot 20,3.50$ & 0.009 & $1 \cdot 34$ & $0.94,1.91$ & $0 \cdot 104$ & $1 \cdot 11$ & $0.82,1.50$ & 0.499 & $1 \cdot 47$ & $1 \cdot 10,1 \cdot 98$ & 0.010 \\
\hline Gender (boys relative to girls) & 1.07 & $0 \cdot 81,1 \cdot 41$ & 0.633 & $1 \cdot 36$ & $1 \cdot 02,1 \cdot 82$ & 0.038 & $0 \cdot 85$ & $0 \cdot 66,1 \cdot 10$ & $0 \cdot 219$ & $1 \cdot 05$ & $0.91,1 \cdot 22$ & 0.493 & 0.57 & $0.48,0.67$ & $<0.001$ \\
\hline \multicolumn{16}{|c|}{ Residential area (reference: urban) } \\
\hline Town & $1 \cdot 18$ & $0 \cdot 87,1 \cdot 61$ & $0 \cdot 297$ & 0.92 & $0.59,1.43$ & 0.702 & $1 \cdot 61$ & $1 \cdot 22,2 \cdot 13$ & 0.001 & $1 \cdot 11$ & $0.93,1.33$ & 0.256 & $1 \cdot 00$ & $0 \cdot 80,1 \cdot 24$ & 0.968 \\
\hline Rural & $1 \cdot 33$ & $0.99,1.77$ & 0.055 & 0.78 & $0.54,1 \cdot 13$ & $0 \cdot 197$ & $1 \cdot 37$ & $1 \cdot 03,1 \cdot 82$ & 0.031 & $1 \cdot 22$ & $1 \cdot 04,1 \cdot 43$ & 0.013 & 1.05 & $0 \cdot 86,1 \cdot 28$ & 0.661 \\
\hline \multicolumn{16}{|l|}{$\begin{array}{l}\text { Parents' education (reference: } \\
\text { secondary or below) }\end{array}$} \\
\hline Post-secondary or college & 0.88 & $0 \cdot 65,1 \cdot 18$ & 0.396 & 0.97 & $0 \cdot 68,1 \cdot 39$ & $0 \cdot 860$ & $0 \cdot 84$ & $0 \cdot 64,1 \cdot 12$ & $0 \cdot 234$ & $0 \cdot 89$ & $0 \cdot 75,1 \cdot 06$ & $0 \cdot 179$ & $0 \cdot 86$ & $0 \cdot 70,1 \cdot 04$ & $0 \cdot 124$ \\
\hline University or above & $0 \cdot 76$ & $0.52,1 \cdot 11$ & $0 \cdot 150$ & $1 \cdot 19$ & $0 \cdot 77,1 \cdot 81$ & 0.434 & 0.90 & $0.66,1.23$ & 0.509 & $0 \cdot 79$ & $0.65,0.97$ & 0.025 & $0 \cdot 80$ & $0.66,0.97$ & 0.026 \\
\hline \multicolumn{16}{|l|}{$\begin{array}{l}\text { Household income (reference: } \\
\leq \$ C A N 50000)\end{array}$} \\
\hline \$CAN $50001-75000$ & 1.43 & $0.91,2.23$ & $0 \cdot 120$ & $1 \cdot 88$ & $1 \cdot 10,3 \cdot 20$ & 0.021 & $1 \cdot 41$ & $0 \cdot 95,2 \cdot 10$ & 0.090 & $1 \cdot 39$ & $1 \cdot 06,1 \cdot 83$ & 0.017 & 0.99 & $0 \cdot 73,1 \cdot 34$ & 0.962 \\
\hline \$CAN $75001-100000$ & 0.89 & $0.57,1.40$ & 0.618 & 1.55 & $0.89,2 \cdot 70$ & 0.120 & $0 \cdot 81$ & $0.53,1.23$ & 0.321 & $1 \cdot 18$ & $0.92,1.50$ & 0.189 & 0.91 & $0.69,1.22$ & 0.539 \\
\hline$>$ \$CAN 100000 & $0 \cdot 89$ & $0.57,1.37$ & 0.588 & 1.08 & $0.63,1.85$ & 0.769 & 0.73 & $0.51,1.03$ & 0.073 & $1 \cdot 03$ & $0 \cdot 84,1 \cdot 27$ & 0.781 & 0.90 & $0.69,1.16$ & 0.409 \\
\hline
\end{tabular}

DQI-I, Diet Quality Index-International.

All analyses were mutually adjusted for variables in the table. All estimates were weighted to represent population estimates. 
suggest the importance of nutrition programmes focusing on improving diet quality among children in the development of school health promotion. One Canadian study has shown that nutrition programmes that are based on comprehensive school health exhibit a greater positive effect on students' diets, PA and overweight reduction than a single nutrition programme ${ }^{(13)}$. More research is needed to examine whether such comprehensive school health approaches that integrate nutrition education, nutrition policy, healthy food services, environmental support and various PA strategies into a whole school model will result in an improvement of HRQOL among children. This may justify broader investments in school programmes to the benefits of health and quality of life among children ${ }^{(13,50)}$.

Major strengths of the present study include the use of a large population-based sample of students, the use of objective measurement of height and weight, the adjustment for sociodemographic factors in the analysis, the use of a validated generic multidimensional HRQOL measure for children, and the application of multilevel regression to account for hierarchical data structure and with weighted analysis to accommodate the survey design effect. Limitations of the study should also be clarified. The observed associations of diet quality, PA and body weight with HRQOL could not be inferred as causality based on the cross-sectional survey design. Since participation in the survey was voluntary, selection bias may have occurred due to possible differences in characteristics between the participants and the non-participants. Our study was conducted in a sample of grade 5 students, which limits the generalizability of the results to other age groups of children. PA and diet assessments in the current study were based on measurement of self-report, and may have been affected by measurement error. The use of objective measures of PA (e.g. pedometers) would allow for more accurate evaluation of PA of students, although this may pose challenges in financial and resource support in large-scale population-based studies ${ }^{(51)}$.

\section{Conclusions}

The present study demonstrated the importance of diet quality, PA and body weight status for HRQOL which will help justify broader implementation of school health programmes that promote healthy eating and active living, as these programmes will help reduce the burden of childhood obesity and improve quality of life.

\section{Acknowledgements}

This research was funded through a contract with Alberta Health and Wellness. The present analysis was further funded through a Canada Research Chair in Population Health and Alberta Innovates Health Solutions Scholarship to P.J.V. All interpretations and opinions are those of the authors. The authors declare that they have no conflict of interests. All authors have participated in the planning of the analysis and writing of the article. Analysis was done by X.Y.W. The authors thank all grade 5 students, parents and schools for their participation in the REAL Kids Alberta evaluation; all of the research assistants and regional health promotion coordinators for the execution of the data collection; and Connie Lu and Dr Stefan Kuhle for data management, validation and quality control.

\section{References}

1. Ebbeling CB, Pawlak DB \& Ludwig DS (2002) Childhood obesity: public-health crisis, common sense cure. Lancet 360, 473-482.

2. Statistics Canada (2010) Canadian Health Measures Survey: Cycle 1 Data Tables, 2007 to 2009. Catalogue no. 82-623-X. http://dsp-psd.pwgsc.gc.ca/collections/collection_2010/statcan/ 82-623-X/82-623-x2010001-eng.pdf (accessed July 2011).

3. Reilly JJ \& Kelly J (2011) Long-term impact of overweight and obesity in childhood and adolescence on morbidity and premature mortality in adulthood: systematic review. Int J Obes (Lond) 35, 891-898.

4. Choudhary AK, Donnelly LF, Racadio JM et al. (2007) Diseases associated with childhood obesity. Am J Roentgenol 188, 1118-1130.

5. Ball GD \& McCargar LJ (2003) Childhood obesity in Canada: a review of prevalence estimates and risk factors for cardiovascular diseases and type 2 diabetes. Can J Appl Physiol 28, 117-140.

6. Wang F \& Veugelers PJ (2008) Self-esteem and cognitive development in the era of the childhood obesity epidemic. Obes Rev 9, 615-623.

7. Falkner NH, Neumark-Sztainer D, Story M et al. (2001) Social, educational, and psychological correlates of weight status in adolescents. Obes Res 9, 32-42.

8. Li Y, Dai Q, Jackson JC et al. (2008) Overweight is associated with decreased cognitive functioning among school-age children and adolescents. Obesity (Silver Spring) 16, 1809-1815.

9. Florence MD, Asbridge M \& Veugelers PJ (2008) Diet quality and academic performance. $J$ Sch Health 78, 209-215.

10. Swinburn BA, Caterson I, Seidell JC et al. (2004) Diet, nutrition and the prevention of excess weight gain and obesity. Public Health Nutr 7, 123-146.

11. Janssen I, Katzmarzyk PT, Boyce WF et al. (2005) Health Behaviour in School-Aged Children Obesity Working Group. Comparison of overweight and obesity prevalence in schoolaged youth from 34 countries and their relationships with physical activity and dietary patterns. Obes Rev 6, 123-132.

12. Brown T \& Summerbell C (2009) Systematic review of school-based interventions that focus on changing dietary intake and physical activity levels to prevent childhood obesity: an update to the obesity guidance produced by the National Institute for Health and Clinical Excellence. Obes Rev 10, 110-141.

13. Veugelers PJ \& Fitzgerald AL (2005) Effectiveness of school programs in preventing childhood obesity: a multilevel comparison. Am J Public Health 95, 432-435.

14. Rampersaud GC, Pereira MA, Girard BL et al. (2005) Breakfast habits, nutritional status, body weight, and academic performance in children and adolescents. $J \mathrm{Am}$ Diet Assoc 105, 743-760.

15. Hughes AR, Farewell K, Harris D et al. (2007) Quality of life in a clinical sample of obese children. Int J Obes (Lond) 31, 39-44. 
16. Schwimmer JB, Burwinkle TM \& Varni JW (2003) Healthrelated quality of life of severely obese children and adolescents. JAMA 289, 1813-1819.

17. Friedlander SL, Larkin EK, Rosen CL et al. (2003) Decreased quality of life associated with obesity in school-aged children. Arch Pediatr Adolesc Med 157, 1206-1211.

18. Williams J, Wake M, Hesketh K et al. (2005) Health-related quality of life of overweight and obese children. JAMA $\mathbf{2 9 3}$, 70-76.

19. Shoup JA, Gattshall M, Dandamudi P et al. (2008) Physical activity, quality of life, and weight status in overweight children. Qual Life Res 17, 407-412.

20. Pinhas-Hamiel O, Singer S, Pilpel N et al. (2006) Healthrelated quality of life among children and adolescents, associations with obesity. Int J Obes (Lond) 30, 267-272.

21. Varni JW, Limbers CA \& Burwinkle TM (2007) Impaired health-related quality of life in children and adolescents with chronic conditions: a comparative analysis of 10 disease clusters and 33 disease categories/severities utilizing the PedsQL 4.0 Generic Core Scales. Health Qual Life Outcomes 16, 43.

22. Swallen KC, Reither EN, Haas SA et al. (2005) Overweight, obesity, and health-related quality of life among adolescents, the National Longitudinal Study of Adolescent Health. Pediatrics 115, 340-347.

23. Yackobovitch-Gavan $\mathrm{M}$, Nagelberg $\mathrm{N}$, Phillip $\mathrm{M}$ et al (2009) The influence of diet and/or exercise and parental compliance on health-related quality of life in obese children. Nutr Res 29, 397-404.

24. Hamiwka LA, Cantell M, Crawford S et al. (2009) Physical activity and health related quality of life in children following kidney transplantation. Pediatr Transplant 13, 861-867.

25. Chen X, Sekine M, Hamanishi S et al. (2005) Associations of lifestyle factors with quality of life (QOL) in Japanese children, a 3-year follow-up of the Toyama Birth Cohort Study. Child Care Health Dev 31, 433-439.

26. Chen X, Sekine M, Hamanishi S et al. (2005) Lifestyles and health-related quality of life in Japanese school children: a cross-sectional study. Prev Med 40, 668-678.

27. Alberta Education (2007) Student Population by Grade, School and Authority, Alberta 2006/2007 School Year. http://education.alberta.ca/apps/eireports/pdf_files/eis1004_ 2007/eis1004_2007.pdf (accessed July 2011).

28. Wille N, Badia X, Bonsel G et al. (2010) Development of the EQ-5D-Y: a child-friendly version of the EQ-5D. Qual Life Res 9, 875-886.

29. Rockett HR, Wolf AM \& Colditz GA (1995) Development and reproducibility of a food frequency questionnaire to assess diets of older children and adolescents. J Am Diet Assoc 93, 336-340.

30. Rockett HR, Breitenbach M, Frazier AL et al. (1997) Validation of a youth/adolescent food frequency questionnaire. Prev Med 26, 808-816.

31. Health Canada (2007) Canadian Nutrient File (CNF). http:// www.hc-sc.gc.ca/fn-an/nutrition/fiche-nutri-data/index-eng. php (accessed July 2011).

32. Kim S, Haines PS, Siega-Riz AM et al. (2003) The Diet Quality Index-International (DQI-I) provides an effective tool for cross-national comparison of diet quality as illustrated by China and the United States. J Nutr 133, 3476-3484.
33. Crocker PR, Bailey DA, Faulkner RA et al. (1997) Measuring general levels of physical activity: preliminary evidence for the Physical Activity Questionnaire for Older Children. Med Sci Sports Exerc 29, 1344-1349.

34. Kowalski KC, Crocker PR \& Faulkner RA (1997) Validation of the physical activity questionnaire for older children. Pediatr Exerc Sci 9, 174-186.

35. Cole TJ, Bellizzi MC, Flegal KM et al. (2000) Establishing a standard definition for child overweight and obesity worldwide, international survey. BMJ 320, 1240-1243.

36. Ravens-Sieberer U, Wille N, Badia X et al. (2010) Feasibility, reliability and validity of the EQ-5D-Y: results from a multinational study. Qual Life Res 19, 887-897.

37. Bize R, Johnson JA, Plotnikoff RC et al. (2007) Physical activity level and health-related quality of life in the general adult population: a systematic review. Prev Med 45, 401-415.

38. Sánchez-López M, Salcedo-Aguilar F, Solera-Martínez M et al. (2009) Physical activity and quality of life in schoolchildren aged 11-13 years of Cuenca, Spain. Scand J Med Sci Sports 19, 879-884.

39. Boyle SE, Jones GL \& Walters SJ (2010) Physical activity, quality of life, weight status and diet in adolescents. Qual Life Res 19, 943-954.

40. Tsiros MD, Olds T, Buckley JD et al. (2009) Health-related quality of life in obese children and adolescents. Int J Obes (Lond) 33, 387-400.

41. Strauss RS, Rodzilsky D, Burack G et al. (2001) Psychosocial correlates of physical activity in healthy children. Arch Pediatr Adolesc Med 155, 897-902.

42. Johnson JA \& Pickard AS (2000) Comparison of the EQ-5D and SF-12 health surveys in a general population survey in Alberta, Canada. Med Care 38, 115-121.

43. Jaeschke R, Singer J \& Guyatt GH (1989) Measurement of health status. Ascertaining the minimal clinically important difference. Control Clin Trials 10, 407-415.

44. Pickard AS, Neary MP \& Cella D (2007) Estimation of minimally important differences in EQ-5D utility and VAS scores in cancer. Health Qual Life Outcomes 5, 70.

45. Walters SJ \& Brazier JE (2005) Comparison of the minimally important difference for two health state utility measures: EQ-5D and SF-6D. Qual Life Res 14, 1523-1532.

46. Lydick E \& Epstein RS (1993) Interpretation of quality of life changes. Qual Life Res 2, 221-226.

47. Norman GR, Sloan JA \& Wyrwich KW (2003) Interpretation of changes in health-related quality of life: the remarkable universality of half a standard deviation. Med Care $\mathbf{4 1}$, 582-592.

48. Wu X, Ohinmaa A \& Veugelers P (2010) Socio-demographic and neighbourhood determinants of health related quality of life among grade five students in Canada. Qual Life Res 19, 969-976.

49. Willems DC, Joore MA, Nieman FH et al. (2009) Using EQ-5D in children with asthma, rheumatic disorders, diabetes, and speech/language and/or hearing disorders. Int J Technol Assess Health Care 25, 391-399.

50. Deschesnes M, Martin C \& Hill AJ (2003) Comprehensive approaches to school health promotion: how to achieve broader implementation? Health Promot Int 18, 387-396.

51. Simen-Kapeu A \& Veugelers PJ (2010) Should public health interventions aimed at reducing childhood overweight and obesity be gender-focused? BMC Public Health 10, 340. 